\title{
La noción de política en la filosofía de Michel Foucault ${ }^{1}$
}

\section{The Notion of Politics in the Philosophy of Michel Foucault A Noção de Política na Filosofia de Michel Foucault}

\author{
Dr. Marcelo Raffin²
}

Recibido: 26 de febrero de 2018 - Aceptado: 27 de marzo de 2018

\begin{abstract}
Resumen
En este artículo, me propongo analizar la noción de "política" en la producción foucaultiana, teniendo en cuenta, en particular, el tratamiento que esa noción recibe en sus investigaciones de 1970 y 1980 (momentos en los que explicita sus ideas, preocupaciones e intereses sobre la política), las definiciones que el filósofo ofrece sobre ella durante este periodo y las investigaciones que se han producido hasta el momento. De esta manera, sostengo que se puede identificar dos nociones fuertes de la política en Foucault, que se oponen entre sí: una ligada al paradigma de la gubernamentalidad y la biopolítica, de carácter diagnóstico y analítico sobre
\end{abstract}

\footnotetext{
1 Este artículo constituye una difusión de resultados parciales de las investigaciones desarrolladas en el ámbito del Consejo Nacional de Investigaciones Científicas y Técnicas (CONICET), de Argentina, y de la Secretaría de Ciencia y Técnica (SECyT) de la Universidad de Buenos Aires (UBA) en el Proyecto UBACyT 20020150100181BA Mod. I La relación verdad-subjetividad en la filosofía de Michel Foucault en los años 1970 y 1980, Programación Científica 2016-2018, del que el autor es director durante los últimos dos años y medio, y retoma, en parte, algunas de las ideas presentadas en eventos científicos y académicos, como el VII Coloquio Internacional de Filosofía Política, organizado por la Asociación Iberoamericana de Filosofía Práctica (AIFP) y la Universidad de La Habana, en La Habana, 22 y 23 de octubre de 2015, el Coloquio «Regards transatlantiques croisés sur les indépendances et critiques post-coloniales du logocentrisme philosophique», organizado por las de París VIII, VII y III, en París, 2 de junio de 2016, y el XVIII Congreso Nacional de Filosofía de Argentina, organizado por la AFRA y la Universidad Nacional de San Juan, en San Juan, 4 al 6 de octubre de 2017. 2 Argentino. Habilitación (HDR - Habilitation à diriger des recherches) y Doctor en Filosofía por la Universidad de París VIII Vincennes-Saint-Denis, Investigador en Filosofía del CONICET en el Instituto de Investigaciones Gino Germani y Profesor Titular Regular de Filosofía, Facultad de Ciencias Sociales de la UBA. Contacto: raffinmarcelo@yahoo.com
} 
el estado de cosas actual, y otra vinculada a la resistencia y las prácticas de libertad, de carácter propositivo y poiético, como aquello que puede llegar a ser. El artículo analiza ambas nociones, pretendiendo con ello superar los abordajes parciales propuestos hasta hoy, así como restituir el gesto del filósofo en su diagnóstico crítico del presente.

Palabras clave: Política - Foucault - biopolítica - gubernamentalidad resistencia

\begin{abstract}
In this article, I propose to analyze the notion of "politics" in foucaultian production, particularly taking into account the treatment this notion receives in his 1970 and 1980 researches (moments in which he explains his ideas, concerns and interests about politics), definitions the philosopher provides during this period and researches taken place so far. In this way, I argue that we can identify two strong notions of politics in Foucault, each other opposed: one linked to the paradigm of government and biopolitics, of a diagnostic and analytical nature on the current state of affairs, and another one linked to the resistance and practices of freedom, with proposal and poietic character, as what it can become. The article analyzes both notions, in order to overcome the partial approaches proposed until today, as well as to restore the gesture of the philosopher in his critical diagnosis about the present.
\end{abstract}

Keywords: Politics - Foucault - biopolitics - government - resistance

\title{
Resumo
}

Neste artigo, proponho-me analisar a noção de "política" na produção foucaultiana, tendo em conta, em particular, o tratamento que essa noção recebe nas suas investigações de 1970 e 1980 (momentos nos que explicita as suas ideias, preocupações e interesses sobre a política), as definições que o filósofo oferece sobre ela durante este período e as investigações que se têm produzido até o momento. Desta maneira, sustenho que se pode identificar duas noções fortes da política em Foucault, que se opõem entre si: uma ligada ao paradigma da governamentalidade e a biopolítica, de caráter diagnóstico e analítico sobre o estado de coisas atual, e outra vinculada à resistência e às práticas de liberdade, de caráter propositivo e poiético, como aquilo que pode chegar a ser. $\mathrm{O}$ artigo analisa ambas as noções, pretendendo com isso superar as abordagens parciais propostas até hoje, assim como restituir o gesto do filósofo no seu diagnóstico crítico do presente.

Palavras-chave: Política - Foucault - biopolítica - governamentalidade - resistência 


\section{Introducción}

Varios han sido, hasta el momento, los intentos de delinear y sistematizar la noción de "política" en el pensamiento foucaultiano. Desde indagaciones que profundizan diversos aspectos que explicitan los modos en que Foucault desarrolla la cuestión del poder como arista fundamental de las sociedades modernas (en términos de guerra civil, dispositivos disciplinarios y gobierno), hasta la afirmación de silencio sobre esta problemática; en todas estas investigaciones, la política es señalada como un elemento parcial y disruptivo en la producción del filósofo ${ }^{3}$. Sin embargo, en ese contexto, la política se presenta como un eje central y decisivo que Foucault hace explícito en sus investigaciones de los años 1970 y que se prolonga hasta sus últimos trabajos de la década siguiente. Más aún, se puede decir que la política atraviesa toda la obra de Foucault como un eje central y decisivo, aunque las preocupaciones, los intereses y la explicitación de las ideas sobre la

3 Cf., entre otros, Blengino, Luis. "Cuestiones de método: la grilla de inteligibilidad epocal-topológica y la lógica estratégica de las correlaciones y sistemas de dominantes en la historia política de la gubernamentalidad en los cursos de Michel Foucault". En "Ágora Filosófica", Universidad Católica de Pernambuco, 17/1, jan/jun (2017); Colombani, M. C., Foucault y lo político. Buenos Aires: Universidad Nacional de La Plata/Prometeo, 2008; Cubides Cipagauta, H. Foucault y el sujeto político. Ética del cuidado de sí. Bogotá: Siglo del Hombre Editores/Universidad Central-IESCO, 2006; Irrera, O. y Vaccaro, S. La pensée politique de Foucault. Paris: Kimé, 2017; Kelly, M. The Political Philosophy of Michel Foucault. New York: Routledge, 2009; Nosetto, L. Michel Foucault y la política. San Martín: UNSAM Edita, 2014; Moreno Pestaña, J. L. Foucault, la gauche et la politique, trad. Sylvain Le Gall. Paris: Textuel, 2010; Sardinha, D. "Um silêncio de Foucault sobre o que é a política". En Castelo Branco, G. y Veiga-Neto, A. (orgs.). Foucault, filosofia \& política. 1. reimp. Belo Horizonte/São Paulo: Autêntica Editora Ltda., Coleção Estudos Foucaultianos, 2013; Simons, Jon (1995), Foucault \& the political. London and New York: Routledge, 1996. De manera más general, Castelo Branco, G. y Veiga-Neto, A. (orgs.), Foucault, filosofia \& política. 1. reimp. Belo Horizonte/São Paulo: Autêntica Editora Ltda., Coleção Estudos Foucaultianos, 2013; Cortés Rodríguez, M. Poder y resistencia en la filosofía de Michel Foucault. Madrid: Biblioteca Nueva, 2010; Díaz Marsá, M. Modificaciones. Ontología crítica y antropología política en el pensamiento de Foucault. Madrid: Escolar y Mayo, 2014; Sferco, S. Foucault y kairós. Los tiempos discontinuos de la acción política. Bernal: Universidad Nacional de Quilmes, 2015. El único trabajo que, en cierta medida, trata de ofrecer un análisis más global de los sentidos de la política en la producción foucaultiana es Terrel, J. Politiques de Foucault, Paris: PUF, 2010. 
política se hacen patentes a partir de los años 1970 y, particularmente, hacia el final de la década y en los primeros años 80 , periodo en el que ofrece, además, cinco definiciones explícitas de la política.

Ahora bien, en mi opinión, a partir de esas definiciones que Foucault da de la política y teniendo en cuenta sus investigaciones e intereses durante estos años, así como los trabajos de investigación a los que acabo de aludir sobre la noción de "política" en la producción del filósofo, se puede concluir que Foucault sostiene, a fin de cuentas, dos nociones o dos "imágenes" fuertes de la política, que se oponen entre sí:

1) por un lado, una noción de la política ligada al paradigma de la gubernamentalidad y la biopolítica, de carácter diagnóstico y analítico, sobre el estado de cosas actual, y

2) por otro, una ligada a las categorías de "resistencia" y de "prácticas de libertad", de carácter propositivo y creador, como aquello que puede llegar a ser.

De esta manera, desde mi perspectiva, se puede reconocer un núcleo fundamental sobre la política en la "obra" ${ }^{4}$ de Foucault, que gira en torno del objetivo de desentrañar de qué manera es producida la sociedad moderna en la tensión entre prácticas de veridicción y prácticas de jurisdicción, es decir, entre economía y Derecho, como mecanismos interno y externo, respectivamente, de la configuración de la vida en su relación con el gobierno. Así, aparece en Foucault una noción de política signada por la idea de "gubernamentalidad" frente a la cual, de todas formas, Foucault postula otra en sentido contrario. Esta última refiere al ejercicio de la resistencia a partir de un trabajo

4 Empleo el término "obra" siendo consciente de la crítica que Foucault formula a esta noción. De todas formas, y como lo señala Didier Éribon en la biografía que le dedica -Michel Foucault (1926-1984). Paris: Flammarion, 1989-, como académico, Foucault entró en una trama de relaciones que lo hizo transformarse en el "autor" de una "obra" respecto de la que se desarrolló un aparato de "comentarios" que pretendieron y pretenden aún restituir su producción a esas figuras de las que siempre buscó separarse. Es, entonces, en este sentido que utilizo el término. 
sobre sí y sobre los otros como posibilidad de crear otra vida y otro mundo (autre vie, autre monde), como vida y mundo diferentes (vie autre, monde autre) a los que se vive y como espacio de libertad, y se centra en las prácticas de subjetivación, dentro de las cuales las relativas a la producción de la verdad revisten un papel fundamental. De este modo, creo que es necesario superar los estudios parciales de la política en Foucault producidos hasta el momento y restituir el gesto foucaultiano del diagnóstico del presente no sólo en términos analíticos de aquello que constituye el estado de cosas vigente, sino también poiético, como aquello que puede llegar a ser. En lo que sigue voy a centrar el análisis en los rasgos más importantes (teniendo en cuenta el acotado espacio del artículo, porque la cuestión amerita mayores desarrollos) de las dos nociones o "imágenes" fundamentales con las que Foucault piensa la política: por un lado, la que aparece ligada al paradigma de la gubernamentalidad y la biopolítica, como punto extremo de su análisis de la producción de la vida en su relación con el gobierno (poder) en la modernidad, y, por el otro, la que refiere al ejercicio de la resistencia y las prácticas de libertad, centrada en los modos de subjetivación y en la ontología crítica del presente como espacio de libertad y creación.

Antes de proceder al análisis propuesto y con el fin de comprender el alcance y los objetivos de mi trabajo, estimo necesario definir aquello que entiendo por "política" en este artículo o, al menos, decir claramente cuál será el alcance que voy a dar a este término. Tomo la noción de "política" en el sentido amplio de creación del orden que contiene a lo "humano" o, para decirlo de otra manera, del continente de lo "humano" en términos de creación y producción. Este "continente", que retoma la antigua categoría de la ciudad (pólis), puede ser comprendido, asimismo, como "comunidad" significativa de acción, de interacción con los otros, y sobre todo de lucha, de enfrentamiento de visiones sobre la vida, sobre los otros y sobre el mundo. La ciudad, como lugar propio de la política y de lo político, es entonces, en mi opinión, un espacio agonal y de creación.

El propósito último que persigue la presente investigación consiste en mostrar que la política constituye un elemento que atraviesa la 
producción de Foucault y que enlaza diferentes intereses y problemáticas de su obra. No comprender este gesto impide captar el sentido global que el filósofo otorga a la política. Esta es la razón por la que me propongo reconstruir una noción no sólo central, sino también singularmente potente de su producción.

\section{Las definiciones explícitas de la política en la producción foucaultiana}

Durante la década de 1970 y a principios de la siguiente, Foucault ofrece cinco definiciones de la política en cuatro momentos diferentes a lo largo de este periodo, en las que va progresando, precisando y haciendo más consistentes los sentidos de lo que entiende por política. Explicito, a continuación, esas definiciones.

1) La definición de la política que el filósofo presenta con ocasión del debate con Noam Chomsky, en 1971, una definición que es dada por la negativa (Foucault se pregunta expresamente "¿por qué no debería interesarme [por la política]?") (Foucault 1994a 493)5. La política es presentada aquí por Foucault como la cuestión más crucial de nuestra existencia, es decir, en sus propias palabras, "la sociedad en la que vivimos, las relaciones económicas en las que funciona y el sistema que define las formas regulares, los permisos y las prohibiciones que rigen regularmente nuestra conducta", a lo que agrega, para reforzar su interés por la política, que "la esencia de nuestra vida está hecha, a fin de cuentas, por el funcionamiento político de la sociedad en la que nos encontramos" (ídem).

2) La definición de la política que Foucault da en La voluntad de saber, en 1976, a propósito de la inversión de la fórmula de Clausewitz con relación al análisis del poder, en un pasaje clave de sus desarrollos sobre esta cuestión (punto 2 "Método" del

5 Toda vez que no se indique lo contario, la traducción es propia. 
capítulo IV "El dispositivo de sexualidad"): la política sería la guerra continuada por otros medios. Foucault piensa entonces la política como la codificación (en parte, pero nunca totalmente) de la multiplicidad de las relaciones de fuerza, sea bajo la forma de la "guerra", sea bajo la forma de la "política" propiamente dicha (Foucault 1995 123). Se trataría entonces para Foucault, si se mantiene la separación entre guerra y política, de dos estrategias diferentes (pero prontas a caer la una en la otra) para integrar estas relaciones de fuerza desequilibradas, heterogéneas, inestables y tensas.

3) Las dos definiciones de la política que Foucault presenta en el curso del Collège de France de 1979, Nacimiento de la biopolítica:

3.1. La que cierra el curso, como el juego de las diferentes artes de gobernar y de sus diferentes ajustes $y$, al mismo tiempo, el debate que suscitan. Esta definición es formulada por Foucault bajo forma de pregunta: “¿Qué es la política, finalmente, si no, al mismo tiempo, el juego de estas diferentes artes de gobernar con sus diferentes ajustes y el debate que ellas suscitan? Es allí, en mi opinión, donde nace la política" (Foucault 2004b 317); y

3.2. La que ofrece en el manuscrito sobre la gubernamentalidad, inserto entre las lecciones del 21 de febrero y el 7 de marzo de 1979, donde la política es definida, en el contexto de las consideraciones sobre la gubernamentalidad, como "generalidad singular", como "aquello que nace con la resistencia a la gubernamentalidad, la primera sublevación, el primer enfrentamiento" (citado por Senellart, notas 134 y 140, apud Foucault 2004a 409 y 407).

Foucault dice concretamente aquí:

"El análisis de la gubernamentalidad como generalidad singular implica que "'todo es político'". Tradicionalmente se confiere dos sentidos a esta expresión:

- Lo político se define para toda la esfera de intervención del Estado. [...] Decir que todo es político, es decir que el Estado está en todas partes, directa o indirectamente. 
- Lo político se define por la omnipresencia de una lucha entre dos adversarios. [...] Esta otra definición es la que corresponde a K. [sic] Schmitt.

La teoría del camarada.

[...]

En suma, dos formulaciones: todo es político por la naturaleza de las cosas; todo es político por la existencia de los adversarios.

Se trata más bien de decir lo siguiente: nada es político sino que todo puede ser politizado, todo se puede volver político. La política no es nada más y nada menos que lo que nace con la resistencia a la gubernamentalidad, la primera sublevación, el primer enfrentamiento" (ibíd. 409)

4) La definición de la política que Foucault formula en la lección del 2 de febrero de 1983, en el curso del Collège de France $E I$ gobierno de sí y de los otros. Aquí Foucault refiere a la política en el contexto específico de su análisis de la parresía (o parrhesia) política en el mundo griego clásico. En particular, las consideraciones que presenta sobre la política están ligadas a la manera en que se separan, se distinguen y se vinculan dos conjuntos de problemas que se derivan del juego de la parresía política. Estos dos conjuntos de problemas conciernen a la politeia y a la dynasteia. La politeia remite a los problemas de la constitución, del marco que define el estatuto de los ciudadanos, sus derechos, la manera de tomar sus decisiones, el modo de elegir a su jefe, etc. Por el contrario, la dynasteia constituye el ejercicio del poder o el juego a través del cual el poder se ejerce efectivamente en una democracia. La parresía política, es decir, el decir verdadero del político, aparece en este contexto como la noción que articula ambas categorías y que garantiza el juego conveniente de la política. Es entonces en este contexto que Foucault sostiene que "los problemas de la dynasteia, los problemas del poder (puissance) son, en sentido estricto, los problemas de la política" (Foucault 2008 146-147), y agrega que nada le "parece más peligroso que ese famoso deslizamiento de la política a lo político, empleado en neutro 
("Io" político)", que en muchos de los análisis contemporáneos sirve para

"(...) enmascarar el problema y el conjunto de los problemas específicos que son los de la política, de la dynasteia, del ejercicio del juego político y del juego político como campo de experiencia con sus reglas y su normatividad, como experiencia en la medida en que ese juego político se ajusta al decir verdadero e implica por parte de aquellos que lo juegan una cierta relación [consigo] mismo y con los otros. Eso es la política." (Ídem).

En consecuencia, en esta definición de Foucault la política aparece ligada al ejercicio de la parresía, es decir, al decir verdadero como práctica de sí que implica una relación consigo mismo y con los otros, al mismo tiempo como juego y como experiencia.

Como se puede apreciar, si bien Foucault se manifiesta sobre la política a lo largo de toda su producción, es sobre todo a partir de los años 70 que se plantea la cuestión de manera más específica y desarrollada. Por lo tanto, voy a intentar reinscribir las definiciones específicas de la política en Foucault en el marco más general de los desarrollos de su producción integral, y sobre todo de aquellos que presenta a partir de los años 70, ligados particularmente a su estudio de la biopolítica y la gubernamentalidad, y al giro que experimenta esta investigación entre el final de los años 1970 y la década siguiente, a partir de la relación verdad-subjetividad-gobierno.

\section{La noción de política ligada al paradigma de la gubernamentalidad y la biopolítica}

La noción de "política" en Foucault, ligada al paradigma de la gubernamentalidad y la biopolítica, refiere a una relación muy particular que el filósofo establece entre la vida y el gobierno, por la cual la vida es modelada por el poder, apresada, sujetada, sometida por él, $y$, sobre todo, configurada de una cierta forma que impide cualquier otra posibilidad. La "gubernamentalidad", como concepto y término 
inventado por Foucault, pretende dar cuenta de un fenómeno propio y específico de la sociedad moderna, como es la configuración de la vida (pero también de la muerte y cuyo epifenómeno central está constituido por la ecuación entre la animalidad y la politicidad), en el marco más general de su propuesta de análisis de la producción de la sociedad moderna como correlato del mercado. Así, concretamente, Foucault concibe la sociedad moderna como el resultado de la tensión entre prácticas de veridicción y prácticas de jurisdicción, que remiten especialmente a los mecanismos interno y externo de funcionamiento del mercado, en los ámbitos particulares de la economía y el Derecho.

La elaboración de la categoría de gubernamentalidad aparece en Foucault en el marco de su gran investigación sobre la biopolítica, que signa los años 70, que el filósofo desarrolló sobre todo por relación a su gran proyecto de "Historia de la sexualidad" y que se desprende -en un sentido, a su vez, como pieza a ser trabajada- del estudio que dedicó a la genealogía de la prisión. En este sentido, cabe destacar que "Historia de la sexualidad", como proyecto de investigación, en parte es y en parte no es una investigación sobre la sexualidad en Occidente. En parte lo es en la medida en que Foucault pretende dar cuenta de la producción histórica de la categoría de sexualidad en las sociedades occidentales en el siglo XIX, y en parte no es sólo eso, pues el proyecto no se detiene allí o no se resume sólo en este trabajo, porque el filósofo se interesa en la sexualidad en la medida en que es expresión de la biopolítica, que define como ese acontecimiento decisivo de la modernidad que marca su tono y define su lógica, en una palabra, como la relación del poder sobre la vida por la cual el poder da una cierta forma a la vida tratando de que no asuma otras, o como él mismo afirma al presentar formalmente el concepto en $L a$ voluntad de saber, tomo I de Historia de la sexualidad, como "aquello que hace entrar la vida y sus mecanismos en el ámbito de los cálculos explícitos y hace del poder-saber un agente de transformación de la vida humana" (Foucault 1995 188). Sin embargo, el dispositivo de sexualidad no es el único acontecimiento decisivo o fundamental de la biopolítica para Foucault. En efecto, al presentar el dispositivo de sexualidad, el filósofo señala, al mismo tiempo, el de la "simbólica de la sangre", como otro dispositivo fundamental con el cual el de la 
sexualidad va a establecer una relación muy especial: el dispositivo de sexualidad será siempre preeminente con relación al de la "simbólica de la sangre" (que había jugado un papel decisivo en los siglos previos al siglo XIX) que, a su vez, se transformará en racismo moderno.

En consecuencia, "Historia de la sexualidad" despliega también y sobre todo un proyecto de análisis político: el de la biopolítica que Foucault explicitará como "gubernamentalidad", en una doble dimensión de poder sobre la vida individual (el sujeto, la subjetividad individual, su "cuerpo" y su "alma") y la vida colectiva (las poblaciones). En este sentido, el propio Foucault afirma que el sexo constituye verdaderamente una cuestión política, un "desafío" o un "reto" "político" ("enjeu politique"), en la medida en que aparece articulando ("il est à la charnière de") los dos ejes a lo largo de los cuales se desarrolló toda la tecnología política de la vida en la modernidad: el de la disciplina y el de la regulación de las poblaciones (ibíd. 191). Foucault refuerza esta idea señalando explícitamente que "el sexo es acceso a la vez a la vida del cuerpo y a la vida de la especie. Es empleado como matriz de las disciplinas y como principio de las regulaciones" (ibíd. 192).

Ahora bien, es sobre todo en términos de la relación del poder, pensado a partir del curso de 1978 (Seguridad, territorio, población), como técnicas y procedimientos de gobierno, con la vida y con la verdad, que Foucault va a desarrollar su trabajo de investigación a partir de esos años 6 . De esta manera, la investigación de "Historia de la sexualidad", que despliega la noción clave de la biopolítica como diagnóstico central de la modernidad, o, dicho de otra manera, la investigación sobre la biopolítica que Foucault desarrolla en el marco de una "Historia de la sexualidad", dará un giro fundamental a partir de fines de la década de 1970 en la medida en que se centrará en los

6 En el curso de 1975-1976, «ll faut défendre la société», Foucault se había ocupado particular y ampliamente de la cuestión del poder e inclusive la había ligado, a través de la noción de "guerra", al poder político, al proponer invertir la famosa fórmula de Clausewitz (Foucault 1997 16). El curso termina, asimismo, con la introducción al problema del poder sobre la vida o "bio-poder" y, finalmente, "biopolítica", que presenta simultáneamente en el último capítulo del tomo I de Historia de la sexualidad, publicado en diciembre de 1976. 
modos en que el sujeto se relaciona consigo mismo por referencia al gobierno y a la verdad. Sin embargo, la relación ya aparece planteada por Foucault en el curso de 1978, en el que define los elementos fundamentales de la gubernamentalidad y la liga claramente a la verdad en la tradición de la pastoral cristiana para, a partir de allí, remontarse a la Antigüedad en los años siguientes. La relación del sujeto con la verdad, que en una primera instancia en Foucault aparece vinculada a la gubernamentalidad, será retomada y reformulada por el filósofo en la torsión que se produce en sus investigaciones en el pasaje de una década a otra, porque a través de su análisis Foucault va a proponer un sentido diferente de la política.

\subsection{La "gubernamentalidad" en los cursos de 1978 y 1979}

El concepto de "gubernamentalidad" constituye una categoría clave y compleja en la producción foucaultiana y es formalmente presentado en el curso del Collège de France Seguridad, territorio, población. Más aún, constituye el eje de este curso, a punto tal que inclusive se lo podría denominar, como el mismo Foucault lo señala, antes que Seguridad, territorio, población, "Una historia de la gubernamentalidad" (Foucault 2004111$)^{7}$. En un pasaje de la lección del $1^{\circ}$ de febrero de 1978, aquella en la que el filósofo propone por primera vez el concepto, explica que por "gubernamentalidad", entiende sobre todo tres cosas (ibíd. 111-112):

1) el conjunto constituido por las instituciones, los procedimientos, análisis y reflexiones, los cálculos y las tácticas, que permiten ejercer esta forma bien específica -aunque muy compleja- de poder que tiene como blanco principal la población, como forma mayor de saber la economía política y como instrumento técnico esencial los dispositivos de seguridad;

7 Foucault dice expresamente: "En el fondo, si hubiera querido dar al curso que comencé este año un título más exacto, no es ciertamente el de "Seguridad, territorio, población", el que habría elegido. Lo que querría hacer ahora, si realmente quisiera hacerlo, sería algo que llamaría une "historia de la "gubernamentalidad"" (ídem). 
2) la tendencia, la línea de fuerza que, en todo el Occidente, no dejó de conducir -y desde hace mucho tiempo- hacia la preeminencia, sobre todos los demás, de ese tipo de poder que se puede denominar el "gobierno": soberanía, disciplina, y que indujo, por un lado, el desarrollo de una serie de aparatos específicos de gobierno y, por otro, el desarrollo de una serie de saberes, $y$, finalmente,

3) el proceso, o más bien el resultado del proceso por el cual el Estado de justicia de la Edad Media, que se transformó en Estado administrativo en los siglos XV y XVI, fue paulatinamente "gubernamentalizado".

No es mi interés presentar aquí un análisis pormenorizado del concepto de "gubernamentalidad" en la producción foucaultiana, sino más bien destacar algunas notas fundamentales, a efectos de mostrar mejor su conexión con una de las nociones de "política" desarrollada por Foucault.

La primera nota de la gubernamentalidad que en mi opinión debe ser subrayada, refiere a la reformulación que con esta categoría el filósofo opera respecto de la cuestión del poder. La gubernamentalidad remite así al problema del "gobierno", entendido, en un sentido general, como determinación de la conducta de los hombres. De allí que Foucault explique de manera fuerte la gubernamentalidad como "gobierno de los hombres", haciendo un trabajo genealógico de los usos del término "gobierno", especialmente en francés, desde los siglos $\mathrm{XV}$ y XVI. Foucault sostiene que este gobierno de los hombres tiene su origen en Oriente -primero en un Oriente precristiano y luego en el Oriente cristiano- bajo dos formas principales: el poder pastoral y la dirección de conciencia. El poder pastoral posee tres rasgos específicos:

1) es un poder que se ejerce sobre una multiplicidad en movimiento (el rebaño en su desplazamiento);

2) es un poder benévolo, es decir, no tiene otra razón de ser que hacer el bien, lo que lo vuelve un poder de cuidado y de salvación; y 
3) es un poder individualizante, es decir, aunque el pastor haga todo lo necesario por la totalidad de su rebaño, también hace todo lo necesario por cada una de las ovejas del rebaño, de suerte que vela por todas y por cada una.

Es a propósito de este último rasgo que Foucault propone la famosa expresión "omnes et singulatim"8, con el fin de caracterizar el poder pastoral y, por supuesto, la gubernamentalidad, como doble movimiento del gobierno de los hombres, tanto en su dimensión individual como colectiva, subrayando especialmente el gobierno de la vida de las poblaciones y los dispositivos de seguridad con sus tres caracteres generales: los espacios de seguridad, la relación con el acontecimiento y la normalización.

En consecuencia, el objeto del curso de 1978, y también, en términos generales, del de 1979, es rastrear la historia del "gobierno" o de aquello que se podría denominar "el arte de gobernar", pero comprendiéndolo en el sentido estricto del ejercicio de la soberanía política. Foucault dice expresamente que quiere estudiar "la manera cómo, dentro y fuera del gobierno y, en todo caso, lo más cerca de la práctica gubernamental, se intentó conceptualizar esa práctica que consiste en gobernar" (Foucault 2004b 4). Ello quiere decir que Foucault quiere determinar "la manera en que se estableció el ámbito de la práctica del gobierno, sus diferentes objetos, sus reglas generales, sus objetivos de conjunto, con el fin de gobernar de la mejor manera posible" (ídem). En suma, concluye, su investigación se refiere al "estudio de la racionalización de la práctica gubernamental en el ejercicio de la soberanía política" (ídem).

A tal fin, va a proceder a través de la elección de un método que se opone a un presupuesto epistemológico fundamental con el que tra-

8 Michel Senellart, que estableció la edición del curso de Foucault de 1978 en el Collège de France, señala aquí que el filósofo alude a la máxima "Salus populi suprema lex esto", cuya primera aparición se encuentra -con un sentido bastante diferente- en Cicerón y que fue retomada a partir del siglo XVI por la mayoría de los teóricos absolutistas. Señala, asimismo, la referencia de Juan, 11, 50 y 18, 14 de La Biblia de Jerusalén (Foucault 2004a 137-138, notas 35 y 39 de la lección del 8 de febrero de 1978). 
bajan la sociología, la historia y la filosofía política, a saber, Foucault va a suponer que los universales, como el soberano, la soberanía, el pueblo, los súbditos, el Estado, la sociedad civil, no existen. Foucault pretende más bien concentrarse en la práctica gubernamental tal como se realiza, pero, al mismo tiempo, tal como es reflexionada y racionalizada, con el objetivo de observar, a partir de allí, cómo pueden efectivamente construirse un cierto número de objetos, sobre cuyo estatuto es necesario interrogarse, como el Estado y la sociedad, el soberano y los súbditos, etc.

En este sentido, en el curso de 1978 Foucault pretende que, a partir del análisis relativamente local y microscópico de las formas de poder caracterizadas por el pastorado, es posible analizar los problemas generales del Estado. Tal como lo afirma en las últimas palabras del curso, un análisis en términos de micropoderes permite realizar, sin ninguna dificultad, el análisis de problemas del nivel del macropoder, como los del gobierno y el Estado (Foucault 2004a 336).

Foucault va a centrar más particularmente sus estudios en el arte de gobernar como ejercicio de la soberanía política, y especialmente en lo que, desde el siglo XVI, se denomina la cuestión de la "razón de Estado" ("ratio status"), puesto que ella constituye uno de los episodios más importantes en la historia del gobierno político en Occidente y, en la medida en que determinó la forma del gobierno político en la modernidad. La razón de Estado consiste en una racionalización de una práctica gubernamental que se ubica entre un Estado que se presenta como dado y un Estado que se presenta para ser construido y edificado. En consecuencia, gobernar según el principio de la razón de Estado, consiste en una práctica que permite al Estado hacerse sólido y permanente, rico y fuerte, frente a todo lo que puede destruirlo.

Pero, al mismo tiempo, en la modernidad, el gobierno político aparece atravesado por la figura del Estado, lo que constituye la segunda nota fundamental de la gubernamentalidad. Sin embargo, Foucault afirma que ello se produce en un movimiento que no se dirige a la integración de la sociedad por el Estado o "estatización de la sociedad", como lo sostuvieron los teóricos de la política en la "primera modernidad" (en especial, en los siglos XVII y XVIII), sino 
a la inversa: como movimiento de la sociedad (mercado) hacia el Estado o, como él mismo lo dice, hacia la "gubernamentalización" del Estado, que tuvo lugar a partir de tres grandes puntos de apoyo: la pastoral cristiana, la nueva técnica diplomático-militar y la policía. Así, Foucault afirma que el Estado es el correlato de una cierta manera de gobernar (Foucault 2004b 8).

La "gubernamentalización" del Estado permitió su supervivencia como "Estado de gobierno". Según este análisis propuesto por Foucault, ello quiere decir que el Estado, en su supervivencia y en sus límites (lo que compete y lo que no compete al Estado, lo que es público y lo que es privado, en una palabra, lo que es estatal y lo que no lo es), sólo debe ser comprendido a partir de las tácticas generales de la gubernamentalidad. El "Estado de gobierno", producido por efecto interior y exterior de la gubernamentalidad, es esencialmente definido por la masa de la población, con su volumen y su densidad, y el territorio en el que esta habita, y corresponde a una sociedad controlada por los dispositivos de seguridad. Este es el corazón de la gubernamentalidad que, según Foucault, insisto, a la inversa de las explicaciones de la teoría política de la "primera modernidad", produce este movimiento de "gubernamentalización" del Estado por medio de la combinación de tres elementos fundamentales: la población, el territorio y la seguridad, como lo enuncia el título del curso de 1978. De ahí que, en la perspectiva foucaultiana, quien dice gubernamentalidad dice no sólo "gobierno de los hombres" sino también "Estado".

En este estudio de la gubernamentalidad, Foucault distingue, sin embargo, dos momentos fundamentales de su desarrollo en el espacio de la modernidad. Un primer momento durante el siglo XVII y la primera mitad del siglo XVIII, como una primera configuración de la gubernamentalidad con sus dos conjuntos de tecnologías del arte de gobernar, el sistema diplomático-militar y la policía, que corresponde al "Estado de policía". Se trata de la gubernamentalidad que Foucault denomina "de los políticos". Un segundo momento, a partir del siglo XVIII avanzado, que corresponde al liberalismo como racionalidad de gobierno y que denomina la "gubernamentalidad de los economistas" (Foucault 2004a 354-362). 
Estos desarrollos que conciernen a la gubernamentalidad van a ser continuados de manera más precisa durante el curso del año siguiente, Nacimiento de la biopolítica, en el que Foucault se propone estudiar, más particularmente, la última forma de gubernamentalidad señalada, aquella que, como el mismo lo dice, "va a dar algunas de las líneas fundamentales de la gubernamentalidad moderna y contemporánea" (Ibíd. 356). En efecto, Foucault va a estudiar el liberalismo como la emergencia de un régimen de verdad en tanto principio de autolimitación del gobierno -que jugará como pieza clave de este nuevo tipo de racionalidad en el arte de gobernar- provisto por la economía política ${ }^{9}$. En sus análisis, el filósofo se ocupará de los rasgos fundamentales que caracterizan esta racionalidad gubernamental y de los desplazamientos, transformaciones e inversiones operados en el siglo $\mathrm{XX}$ en relación con la doctrina liberal tradicional, que se impusieron como nueva forma de racionalidad gubernamental bajo el nombre de "neoliberalismo".

\subsection{Los desarrollos de las conferencias " "Omnes et singulatim»: hacia una crítica de la razón política"}

Finalmente, estimo que este análisis de la noción de "gubernamentalidad" no podría dejar de considerar un texto que, poniendo en perspectiva las características y las conclusiones generales sobre esta cuestión que acaban de ser consideradas, se transformó en una suerte de hito en la materia. Me refiero a " "Omnes et singulatim»: hacia una crítica de la razón política", que Foucault presenta bajo la forma de conferencias en la Universidad de Stanford, en California, en octubre de 1979, y que será publicado en 1981. En este texto Foucault condensa los rasgos fundamentales de la gubernamentalidad que acabo de analizar y los vincula claramente con los desarrollos que

9 Este procedimiento de análisis remite al mismo problema que Foucault se había planteado respecto de la locura, la enfermedad, la delincuencia y la sexualidad, en el que pone en evidencia la relación que siempre estableció en sus investigaciones entre regímenes de verdad y formas específicas del ejercicio del poder, y la producción concomitante de ciertos saberes y de ciertas formas "humanas" (ibíd. 21 y 22). 
desplegará en los próximos años, sobre todo en lo que hace al polo de la individualidad o, como él dice, al problema de la identidad en relación con el problema del "poder individualizante", así como al de la liberación a través del ataque de la racionalidad política (Foucault 1994c 136 y 161).

Se podría decir que el hilo conductor o la idea directriz que guía estas conferencias es el gobierno de los individuos por su propia verdad, a partir del análisis de los vínculos entre la racionalización y el poder. En este sentido, en las dos conferencias Foucault presenta las conclusiones a las que llegó en una investigación que venía desarrollando desde hacía dos años y que resume como "el análisis histórico del arte de gobernar". ¿Qué quiere decir con ello? ¿A qué responde esta afirmación y cuál es su valor en este análisis de largo aliento de su producción que propongo? Mostrar el vínculo entre el gobierno en tanto dirección de conductas y los modos de subjetivación, es decir, responder a la pregunta de saber cómo llegamos a ser quienes somos y como somos.

Es probable que el valor más importante de las conferencias "Omnes et singulatim" resida en las últimas palabras que Foucault pronuncia cuando explica los postulados de base sobre los que reposa su investigación en curso desde hace dos años, lo que nos permite comprender el giro que da su trabajo en ese momento. La primera observación de Foucault consiste en afirmar claramente que el poder no es una sustancia sino un tipo particular de relaciones entre individuos y que su rasgo distintivo reside en la determinación de la conducta de los hombres más o menos enteramente, pero nunca de manera exhaustiva o coercitiva. Nuevamente es aquí donde Foucault desdobla expresamente el poder en "gobierno" empleando este término. Al mismo tiempo, se ocupa de aclarar que no hay poder sin rechazo o revuelta en potencia. La cuestión de la resistencia ya había sido planteada por Foucault en La voluntad de saber y en el curso de 1976, Defender la sociedad, al sostener que allí donde hay poder hay resistencia (Foucault 1995 125) y se continúa en los cursos de 1978 y 1979 pues, entre otros aspectos, ya en el curso de 1978 Foucault se detiene en las "contra-conductas" y en su importancia como actos de resistencia al 
pastorado y a la gubernamentalidad, desde el final de la Edad Media y al comienzo de la modernidad hasta el siglo XIX.

Estamos aquí ante un punto de inflexión fundamental entre las dos nociones de política que distingo en la obra foucaultiana. Foucault redefine su trabajo de diagnóstico en términos de gobierno como dirección o determinación de la conducta de los hombres pero, al mismo tiempo, insiste en la posibilidad de la resistencia, la rebelión y la sublevación. Según su posición, este acto de resistencia al gobierno se apoya y reconoce como punto de partida la crítica de la racionalidad de las relaciones de poder, sean cuales fueren.

Por lo tanto, la noción de "política" ligada a la gubernamentalidad y a la biopolítica tiene más bien un valor diagnóstico y analítico del estado de cosas vigente, frente a la cual, de todas formas, Foucault propone otra en sentido inverso: el de la posibilidad de resistir a ese estado de cosas y, eventualmente, crear otro. En este sentido, Foucault ofrece otra noción de la política, ligada a la posibilidad de la resistencia, la creación (lo que tradicionalmente se denomina el gesto "poiético" de la política) y al ejercicio de la libertad, que permite la resistencia al poder/gobierno y la institución de un nuevo orden, de la que me ocuparé en el apartado siguiente.

\section{La noción de política ligada a la resistencia y a las prácticas de libertad}

La noción de "política" ligada a la resistencia, la creación y las prácticas de libertad en Foucault aparece desde la formulación misma de la noción de "política" ligada al paradigma de la gubernamentalidad y de la biopolítica. En efecto, tal como se señaló en el apartado anterior, ya desde La voluntad de sabery desde el curso de 1976, Foucault sostiene que allí donde hay poder hay resistencia, y a partir de la reformulación del problema del poder en términos de gobierno desde el curso de 1978 que, al tiempo que el gobierno es pensado como dirección o determinación de la conducta, es necesario también señalar que conlleva la posibilidad de la resistencia, la rebelión y la sublevación. Vale decir 
que la noción misma de la política ligada a la gubernamentalidad y a la biopolítica contiene ya en sí la posibilidad de su contrario, es decir, de la resistencia y de la institución de un nuevo orden.

Ahora bien, en el giro dado por la investigación sobre la biopolítica desde los años 70 a los 80 la noción de "política" entendida como resistencia a la gubernamentalidad o como ejercicio de poder en sentido inverso a ella queda explicitada, en particular, a través de las nociones de "prácticas de sí" y de "parresía", que refieren a la abierta preocupación foucaultiana por la relación del sujeto con la verdad o, mejor dicho, de la subjetividad con los juegos de verdad, atravesada por el problema del gobierno, asentada a su vez en la categoría de "prácticas de libertad". Las nociones de "prácticas de sí" y de "parresía" remiten muy especialmente a lo que Foucault denomina "modos de subjetivación", es decir, a la manera en que el sujeto se relaciona consigo mismo por referencia al gobierno y a la verdad o, como él mismo sostiene en este momento, reformulando y precisando los términos, por referencia a las "técnicas de gubernamentalidad" y a los "modos de veridicción"10. En esa relación, las prácticas relativas a la producción de la verdad desarrollarán un papel fundamental. Así, Foucault inscribe las categorías de "prácticas de sí y de "parresía" en el marco de su análisis de las formas de la producción o la manifestación de la verdad en el mundo antiguo o, como él las denomina, a partir del adjetivo griego "alethurgés", que significa "aquel que dice la verdad", como formas "aletúrgicas" o "aleturgía"11.

10 "La articulación entre los modos de veridicción, las técnicas de gubernamentalidad y las prácticas de sí, constituye, en el fondo, lo que siempre traté de hacer" (Foucault 2009 10), un señalamiento que Foucault ya había hecho en el curso del año 1983 (Foucault 2008 3-8 y 42).

11 Cf. las primeras lecciones del curso de 1980 Del gobierno de los vivientes, donde Foucault explica: "forjando a partir de $\lambda \eta \theta 0 u \rho \gamma \varsigma$ la palabra ficticia alêthourgia, la aleturgía, podría denominarse "aleturgía" el conjunto de los procedimientos posibles, verbales o no verbales, por los que se saca a la luz lo que se plantea como verdadero por oposición a lo falso, a lo oculto, a lo indecible, a lo imprevisible, al olvido y decir que no hay ejercicio del poder sin algo así como una aleturgía". "Lección del 9 de enero" (Foucault 2012 8). 


\subsection{Las "prácticas de si" y el "souci de soi"}

De este modo, Foucault piensa diferentes "prácticas de si", que va a rastrear en el mundo antiguo y tardo-antiguo, pero para pensar el mundo moderno. En este sentido, son fundamentales los tomos II, III y IV de Historia de la sexualidad, donde Foucault lleva a cabo este trabajo, pero también los últimos cursos a partir del año 1980, que incluyen, además de los del Collège de France, el dictado en la Universidad Católica de Lovaina en 1981, Obrar mal, decir la verdad. La función de la confesión en la justicia.

Ahora bien, la noción de "práctica de sí" se inscribe en el marco del estudio foucaultiano de la "inquietud" o "preocupación por sí mismo" ("souci de soi"), que va a dar lugar a una cultura del "cuidado de sí". El "souci de soi" remite a la idea de inquietarse o preocuparse por uno mismo como un trabajo sobre sí, como un cuidado sobre sí y como una aplicación a sí mismo. Pero esa "inquietud" o "preocupación por sí mismo", en el marco de una cultura del "cuidado de sí", constituye al mismo tiempo un trabajo que implica a los otros o, para decirlo de otra manera, que está atravesado por la dimensión de la alteridad. Cuidar de sí mismo es, en la interpretación foucaultiana, cuidar también de los otros, preocuparse por los otros, no sólo en la medida en que el cuidado va a estar dirigido también a los otros, sino porque, aun pensado desde la instancia meramente individual, implica a los otros.

La noción de "cuidado de sí" en Foucault aparece en sus últimas investigaciones, en particular, en los tomos II y III de Historia de la sexualidad, de los cuales el tercero lleva por título justamente esa expresión (Le souci de soi), y en sus últimos cursos, sobre todo en $L a$ hermenéutica del sujeto, el curso de 1981-1982.

Es en el seno de estas prácticas constitutivas de la "inquietud de sí" que Foucault va a elaborar la noción de "prácticas de sí" como prácticas fundamentales en la historia de la subjetividad occidental, en tanto modos de subjetivación o de construcción de sí mismo. Foucault concebirá las "prácticas de sí" como "técnicas de sí" o "artes de la existencia", es decir, como él mismo las define como 
"(...) prácticas meditadas y voluntarias mediante las cuales los hombres, no sólo se fijan reglas de conducta, sino que buscan transformarse a sí mismos, modificarse en su ser singular, y hacer de su vida una obra que presente ciertos valores estéticos y responda a ciertos criterios de estilo" (Foucault 1994a 16-17).

La noción de "prácticas de sí" es desarrollada en particular por Foucault en el tomo II de Historia de la sexualidad. Es por esta vía que la investigación de historia de la sexualidad se vuelve asimismo una investigación sobre las prácticas y los modos de subjetivación que desembocaron en la formación de un sujeto, y sobre todo de un sujeto moral. Mediante ello, Foucault pretende entonces analizar cómo el sujeto puede ejercer el poder sobre sí mismo, pero ya no en el sentido de una sujeción, sino en los términos de la autoformación o de la autoconstrucción según ciertos ideales económicos, dietéticos, estéticos, en una palabra, según sus propios deseos, es decir, una subjetividad que ejercerá el gobierno de sí misma.

De esta suerte, Foucault sostiene que esta problematización de la sexualidad, como ámbito de experiencia moral planteada por la cultura grecolatina, está ligada a un conjunto de prácticas que ciertamente han tenido una importancia considerable en las sociedades contemporáneas como "prácticas" o "técnicas de si". Foucault subraya que estas "artes de la existencia" o "técnicas de sí" sin duda perdieron una cierta parte de su importancia y de su autonomía cuando fueron integradas con el cristianismo, en el ejercicio de un poder pastoral, y luego, más tarde, en prácticas de tipo educativo, médico o psicológico. En todo caso, el estudio de la problematización del comportamiento sexual en la Antigüedad es considerado por el filósofo como uno de los primeros capítulos de la historia general de las "técnicas de sí".

En consecuencia, en la genealogía de la sexualidad propuesta por Foucault, el filósofo analiza las prácticas por las cuales los individuos fueron llevados a prestarse atención a sí mismos, a descifrarse, a reconocerse y a confesarse como sujetos de deseo, haciendo jugar entre sí una cierta relación que les permitió descubrir la verdad de 
su ser en el deseo, y a ejercer un cierto poder sobre sí mismos como autogobierno. En esto consistió pues el giro concreto del "poder" hacia el "gobierno" como gobierno de sí y, al mismo tiempo, como "gobierno de los otros". Este desplazamiento del problema del "poder" hacia el problema del "gobierno" se hace explícito en este periodo con estos componentes concretos pero, tal como se señaló en el apartado anterior, ya se había producido, en términos generales, en el curso de 1978, cuando Foucault se había planteado el problema de la gubernamentalidad en tanto deriva específica de la biopolítica, como "gobierno de los hombres".

Siguiendo la línea de la formación del sujeto occidental como sujeto de deseo y del autogobierno, en el tomo II de Historia de la sexualidad Foucault sostiene expresamente, en un momento central de la obra, que pretende buscar "cómo los individuos fueron llevados a ejercer sobre sí mismos, y sobre los demás, una hermenéutica del deseo en la que el comportamiento sexual fue sin lugar a dudas la ocasión pero no ciertamente el ámbito exclusivo" (ibíd. 11). Pero para comprender cómo el individuo moderno podía hacer la experiencia de sí mismo como sujeto de una "sexualidad", le parece "indispensable despejar antes la manera en que, durante siglos, el hombre occidental se vio llevado a reconocerse como sujeto de deseo (ibíd. 11-12).

A tal fin, Foucault cree conveniente buscar en la Antigüedad las formas y las modalidades de la relación a sí mismo por las que el individuo se constituye y se reconoce como sujeto a partir de una hermenéutica de sí. Esta "hermenéutica del sujeto" como "sujeto de deseo" abre el camino a los estudios foucaultianos sobre el mundo antiguo y sobre la relación entre el sujeto y la verdad, o más bien entre la subjetividad y los juegos de verdad.

Retomando la noción de "souci de soi" como preocupación y cuidado de sí en Foucault, en cuyo marco se inscriben las "prácticas de sí", es necesario destacar además que dicha noción remite al gobierno y a la política. En efecto, en la producción del filósofo ella expresa un proyecto ético, que pasa también por un proyecto político y que implica un espacio de libertad. 
Como se señaló, Foucault inscribe la categoría de "souci de soi" en el marco de su análisis de los "modos de subjetivación". En esta línea, Foucault propone un recorrido en dirección inversa al de la cronología para pensar la subjetividad occidental en su relación con la verdad: parte de la modernidad con el dispositivo de la sexualidad, pasa luego a la pastoral cristiana de la carne, en la que se ocupa en particular del dispositivo de la confesión, para llegar finalmente a la Antigüedad, donde aborda las "técnicas de vida" en la época del cuidado de sí mismo. Este recorrido pretende analizar las diferentes prácticas mediante las cuales el sujeto se constituye a sí mismo como sujeto moral y el modo en que, para hacerlo, se inscribe en juegos de verdad. En estas prácticas, la relación del sujeto consigo mismo pasa a través del conocimiento de la verdad que el sujeto debe descubrir en sí mismo y descifrar. Es a este trabajo de "descubrimiento", "desciframiento" o "interpretación" de la verdad en sí mismo que Foucault denomina "hermenéutica del sujeto" y que dará origen al curso de 1982. La problemática central del curso gira en torno de la relación del sujeto con la verdad por referencia al gobierno de sí y de los otros, pero inscripta en el marco más general del cuidado de sí mismo. El curso es, en efecto, una historia del cuidado de sí mismo o de la época del cuidado de sí mismo, que se extiende a lo largo de un milenio, desde los tiempos de Sócrates hasta las escuelas filosóficas del helenismo y de la civilización romana.

\subsection{La "parresía"}

Ahora bien, el cuidado de sí aparece enmarcado sobre todo en una práctica de subjetivación específica, la del decir verdadero, auténtico o franco, la "parresía", que Foucault presenta hacia el final de La hermenéutica del sujeto y que desarrolla en sus dos últimos cursos en el Collège de France, en 1983 y 1984.

La parresía, como modo de relación del sujeto consigo mismo por referencia al gobierno y a la verdad, ya no remite a una subjetividad únicamente sometida al gobierno o modelada por él, sino más bien a un sujeto resistente y a la idea de la existencia como "obra" y como 
obra bella. Esta última noción es utilizada por Foucault, al referirse a las prácticas de subjetivación en su relación con los juegos de verdad en el mundo antiguo, bajo la expresión de "estética de la existencia", en la que el juego de la verdad en que se inscribe esta tarea de dar forma bella a la propia vida no tiene la forma de la norma o la obediencia, sino más bien de una universalidad sin ley.

La parresía remite al objetivo de analizar bajo qué forma, en su acto de decir la verdad (dire vrai), el individuo se constituye a sí mismo y es constituido por los otros como sujeto que sostiene un discurso de verdad, es decir, bajo qué forma se presenta, ante sí mismo y ante los demás, aquel que dice la verdad; en una palabra, cuál es la forma del sujeto que dice la verdad. Foucault encuentra todo un juego de prácticas en la cultura antigua que implican la predicación de la verdad sobre sí mismo, que constituyen una "cultura de sí" y que requirieron de un personaje necesario e indispensable sin el cual no podrían haber tenido lugar: se trata de un otro que escucha, que incita a hablar y que también habla y, sobre todo, que posee la cualidad del decir verdadero, auténtico o franco, que es justamente la parresía.

Foucault concluye que la parresía es "el coraje de la verdad en aquel que habla y asume el riesgo de decir, a pesar de todo, toda la verdad que piensa pero es también el coraje del interlocutor que acepta recibir como verdadera la verdad hiriente que escucha" (Foucault, 2009, p. 14). Foucault pretende llevar estos desarrollos sobre la parresía al análisis de la relación entre la existencia como obra y el decir verdadero, en el sentido en el que este coraje de la verdad se orienta a dar forma y estilo a la vida. A partir del contraste del discurso verdadero entre el Alcibíades y el Laques, Foucault destaca, en este último diálogo, el decir verdadero que tiene el papel y la finalidad de dar una cierta forma al bíos, es decir, a la vida, a la existencia. Este discurso de rendición de cuenta de sí debe definir la figura visible que los humanos deben dar a su vida. Este decir verdadero afronta aquí el riesgo y el peligro de decir a los hombres cuánto coraje les será necesario para dar a su vida un cierto estilo y cuánto les costará. El análisis contrastivo de estos dos diálogos permite a Foucault sostener que nos encontramos aquí ante el punto de partida de dos grandes líneas de desarrollo de 
la veridicción socrática a través de la filosofía occidental: una que va hacia la metafísica del alma (el Alcibíades) y la otra que va hacia una estilística de la existencia (el Laques). Con este análisis, Foucault pretende desarrollar una historia de lo que se podría denominar la "estética de la existencia", es decir, mostrar

"(...) cómo, con la emergencia y la fundación de la parresía socrática, la existencia (el bíos) fue constituida en el pensamiento griego como un objeto estético, como objeto de elaboración y de percepción estética: el bíos como obra bella. Tenemos aquí la apertura de un campo histórico de una gran riqueza." (Foucault 2009 149).

Foucault subraya que todo este aspecto de la historia de la subjetividad como obra bella ha estado eclipsado y dominado, naturalmente, por la historia de la metafísica como ontología del alma.

Aquí Foucault focaliza su investigación en el caso del cinismo (en su forma antigua), en la medida en que en el cinismo, modo de vida y parresía se encuentran directa e inmediatamente ligados uno a otro como articulación entre forma de vida y decir verdadero, entre vivir de un cierto modo y abocarse a decir la verdad.

Para Foucault, la figura del cinismo es la ocasión de una reevaluación radical de la verdad filosófica, restituida ahora de lado de la praxis, de la puesta a prueba de la vida y de la transformación del mundo. La cuestión de la verdad en los cínicos será planteada al nivel de la vida misma y, más específicamente, de su materialidad, permitiendo de esta manera poner en evidencia aquello que resiste absolutamente. El gesto del cinismo consiste en vivir según los principios de la verdad, de suerte que la verdad misma se vuelve insoportable en la medida en que abandona el ámbito de los discursos para encarnarse en la existencia. Pero la "vida verdadera" ("vraie vie") sólo puede manifestarse como "vida otra" ("vie autre"). La vida verdadera se instituye así como una apelación a la crítica y a la transformación del mundo. En efecto, en sus últimos cursos Foucault muestra cómo esta vida otra constituye, al mismo tiempo, la crítica del mundo existente y comprende la invocación a un "mundo otro" ("monde autre"). La vida verdadera se 
manifiesta entonces como una vida otra que hace estallar la exigencia de un mundo diferente.

La cuestión de la preocupación por sí mismo (souci de soi) adquiere con el cinismo una nueva dimensión que permite a Foucault afirmar que no se trata de un ejercicio solitario, sino de una práctica social e incluso de una invitación al buen gobierno de los hombres (preocuparse correctamente por uno mismo con el fin de poder preocuparse correctamente por los otros), de suerte que la preocupación por sí mismo se vuelve exactamente una preocupación por el mundo ${ }^{12}$.

Es en este punto donde, creo, aparece la clave que nos permite seguir pensando el "souci de soi" a través de la parresía como un instrumento de construcción ético-político de nuestras sociedades. La parresía permite hacer coincidir nuestro pensamiento con nuestras acciones, pero sólo en la medida en que es acción sobre sí junto con otros. Dar forma y estilo a una vida permite romper los moldes que hacen que la vida y su mundo sean sólo concebidos en un único sentido, es decir, permite pensar la vida y su mundo como una vida y un mundo diferentes al que vivimos. Este trabajo de imaginación y de construcción de vidas y mundos diferentes sólo es posible junto con otros. De esta

12 Si en sus desarrollos acerca de la parresía y el acto "político" de hacer coincidir el pensamiento con la vida Foucault toma el modelo del cinismo, creo, de todas formas, que no hay que desestimar otro modelo que aparece en esta misma serie de investigaciones y que precede el ejemplo de los cínicos: es el caso del "Sócrates parresiasta". En mi opinión, es fundamental analizar específicamente las implicancias de esta figura respecto de la producción de la verdad como parresía, con el fin de evaluar el papel de Sócrates en la relación entre ética y política propuesta por Foucault respecto del decir verdadero como pieza clave de la creación y la producción política. A mayor abundamiento, cf. mi artículo "La interpretación foucaultiana de la figura de Sócrates en la producción de la parresía", en Dorsal. Revista de Estudios Foucaultianos 2 (junio 2017): 49-65. Mi hipótesis en dicho artículo consiste en interrogar la interpretación foucaultiana de un "no compromiso político" de Sócrates, en la medida en que el gesto parresiástico socrático, analizado por Foucault al nivel de la ética, en términos de la preocupación por el gobierno y la estética de la existencia, implica, desde mi perspectiva, una dimensión política, puesto que, aun en este análisis en principio puramente "ético", el gobierno de sí conlleva el gobierno de los otros y la técnica de existencia está atravesada por la alteridad en un ejercicio conjunto de creación, producción y transformación de sí y del mundo. 
manera, el cuidado de sí, es también, al mismo tiempo, cuidado de los otros, porque la parresía sólo puede tener lugar junto con otros.

\subsection{Las "prácticas de libertad"}

El análisis de la política como resistencia a la gubernamentalidad e institución de un nuevo orden se asienta, a su vez, en la categoría foucaultiana de "prácticas de libertad", que remite al análisis crítico del presente como una "ontología crítica de nosotros mismos". En este sentido, es necesario comprender que la libertad es, para Foucault, un presupuesto de la vida y no una consecuencia de los poderes o un permiso otorgado. Justamente, la idea foucaultiana de libertad consiste en sostener que, puesto que hay libertad, hay relaciones de poder, y no a la inversa. En "La ética de la inquietud de sí como práctica de la libertad" (Foucault 1994d 720) el filósofo lo expresa muy claramente: "si hay relaciones de poder a través de todo campo social, es porque hay libertad en todas partes". Foucault concibe entonces las "prácticas de libertad" como el ejercicio de la libertad en tanto resistencia a los poderes, en la relación que el viviente mantiene consigo mismo, que le permite volverse el sujeto de su propia existencia.

\section{Epílogo}

Llegados a este punto, estamos en condiciones de recapitular nuestro punto de partida y apreciar de qué manera, en la obra foucaultiana, se dibujan dos "imágenes" o dos nociones contrapuestas acerca de la política, que el filósofo hace patentes hacia finales de la década de 1970 y a principios de la siguiente. La referida al diagnóstico del mundo capitalista, signado por la racionalidad liberal y neoliberal (que, en el análisis foucaultiano, se traduce en las categorías de gubernamentalidad y biopolítica), que contiene en sí la semilla de otra noción que se opone a ella, de carácter propositivo, y que permite desarticularla. Esta otra noción refiere a la resistencia como ejercicio del poder/gobierno y la libertad. Con este trabajo he pretendido mostrar cómo ambas nociones refieren a la política en Foucault, tratando 
de superar los abordajes que hasta ahora se han producido sobre esta cuestión que, en líneas generales, sólo ponen el acento en una de las imágenes señaladas. En mi opinión, es fundamental destacar ambas nociones de la política en la producción foucaultiana porque, de lo contrario, se soslayaría el gesto del filósofo en su diagnóstico crítico del presente.

En este sentido, ambas nociones dan buena cuenta de la noción de "política" con la que he leído el concepto en la producción foucaultiana, es decir, tanto como espacio agonal, de enfrentamiento de visiones sobre la vida, sobre los otros y sobre el mundo, así como "comunidad" significativa de acción, de interacción con los otros y de creación e imaginación intersubjetiva y colectiva.

De esta manera, se puede comprender también la potencialidad y el valor de las nociones de la política en Foucault, en la medida en que permiten aún tanto un diagnóstico rico y fructífero sobre el presente, sobre la arena política presente, como un proyecto a construir, que es siempre un trabajo sobre sí y con los otros, y que nos ofrece la posibilidad de crear nuevas formas de vida y de imaginar otros horizontes de sentido, aunque reconociendo que no se puede pedir al pensamiento foucaultiano prescripciones o recetas definitivas.

En suma, las nociones de política en Foucault forman parte de la colección de conceptos-herramientas a ser explotados en la "cantera" de su producción, como una suerte de tesoro escondido que todavía nos resta descubrir. El gran valor de las ideas de Foucault reside en las posibilidades que nos abren ante las situaciones concretas que nos tocan vivir y ante las que debemos hacer uso de nuestra potencia, nuestra creación y nuestra libertad.

\section{Bibliografía}

Blengino, Luis. "Cuestiones de método: la grilla de inteligibilidad epocal-topológica y la lógica estratégica de las correlaciones y sistemas de dominantes en la historia política de la gubernamentalidad en los cursos de Michel Foucault". Ágora Filosófica, Universidad Católica de Pernambuco, 17/1, jan/jun (2017). 
Castelo Branco, Guilherme. "Apresentação 1 - Os nexos entre subjetividade e política" y "Agonística e palavra: as potências da liberdade". En Foucault, filosofia \& política, Castelo Branco, Guilherme y Veiga-Neto, Alfredo (orgs.). Belo Horizonte/São Paulo: Autêntica Ed., 2011.

Colombani, María Cecilia. Foucault y lo político. Buenos Aires: Universidad Nacional de La Plata/Prometeo, 2008.

Cubides Cipagauta, Humberto. Foucault y el sujeto político. Ética del cuidado de sí. Bogotá: Siglo del Hombre Editores/Universidad Central-IESCO, 2006.

Cortés Rodríguez, Miguel Ángel. Poder y resistencia en la filosofía de Michel Foucault. Madrid: Biblioteca Nueva, 2010.

Díaz Marsá, Marco. Modificaciones. Ontología crítica y antropología política en el pensamiento de Foucault. Madrid: Escolar y Mayo, 2014.

Foucault, Michel. La volonté de savoir, tomo I de Histoire de la sexualité. Paris: Gallimard, 1995.

Foucault, Michel, L'usage des plaisirs, Histoire de la sexualité, tome II. Paris: Gallimard, 1994a.

Foucault, Michel. Le souci de soi, Histoire de la sexualité, tome III. Paris: Gallimard, 1994b.

Foucault, Michel. «Omnes et singulatim»: vers une critique de la raison politique». En Dits et écrits IV 1980-1988, n² 291, 134-161, Paris: Gallimard, 1994c, que retoma «"Omnes et singulatim": Towards a Criticism of Political Reason», trad. De P. E. Dauzat, Universidad de Stanford, 10 y 16 de octubre de 1979, y publicado por McMurrin, S. (ed.). The Tanner Lectures on Human Values, t. II, Salt Lake City, University of Utah Press, 1981.

Foucault, Michel, «L'éthique du souci de soi comme pratique de la liberté». En Dits et écrits IV 1980-1988, n² 291, 134-161. Paris: Gallimard, 1994d.

Foucault, Michel. «ll faut défendre la société». Cours au Collège de France. 1975-1976. Paris: Gallimard-Seuil-EHESS, 1997.

Foucault, Michel. Sécurité, territoire, population. Cours au Collège de France. 1977-1978. Paris: Seuil/Gallimard, 2004a.

Foucault, Michel. Naissance de la biopolitique. Cours au Collège de France. 1978-1978. Paris: Seuil/Gallimard, 2004b.

Foucault, Michel. Du gouvernement des vivants. Cours au Collège de France. 1979-1980. Paris: Seuil/Gallimard, 2012. 
Foucault, Michel. L'herméneutique du sujet. Cours au Collège de France. 1981 1982. Paris: Seuil/Gallimard, 2001.

Foucault, Michel. Le gouvernement de soi et des autres. Cours au Collège de France. 1982-1983. Paris: Seuil/Gallimard, 2008.

Foucault, Michel. Le courage de la vérité, Le gouvernement de soi et des autres II. Cours au Collège de France. 1984. Paris: Seuil/Gallimard, 2009.

Irrera, Orazio y Vaccaro, Salvo. La pensée politique de Foucault. Paris: Kimé, 2017.

Kelly, Mark. The Political Philosophy of Michel Foucault. New York: Routledge, 2009.

Moreno Pestaña, José Luis. Foucault, la gauche et la politique, trad. Sylvain Le Gall. Paris: Textuel, 2010;

Nosetto, Luciano. Michel Foucault y la política. San Martín: Buenos Aires, UNSAM Edita, 2014.

Raffin, Marcelo. "La interpretación foucaultiana de la figura de Sócrates en la producción de la parresía", en Dorsal. Revista de Estudios Foucaultianos 2 (junio 2017): 49-65.

Sardinha, Diogo. "Um silêncio de Foucault sobre o que é a política". En Castelo Branco, Guilherme y Veiga-Neto, Alfredo (orgs.). Foucault, filosofia \& política, Belo Horizonte/São Paulo: Autêntica Ed., 2011.

Senellart, Michel. «Situation des cours». En Foucault, Michel. Sécurité, territoire, population. Cours au Collège de France. 1977-1978. Paris: Seuil/ Gallimard, 2004a.

Simons, Jon, Foucault \& the political. London and New York: Routledge, 1996.

Sferco, Senda. Foucault y kairós. Los tiempos discontinuos de la acción política. Bernal: Universidad Nacional de Quilmes, 2015.

Terrel, Jean. Politiques de Foucault, Paris: PUF, 2010. 